\title{
Psychosis from a Bath Salt Product Containing Flephedrone and MDPV with Serum, Urine, and Product Quantification
}

\author{
Stephen L. Thornton • Roy R. Gerona • \\ Christian A. Tomaszewski
}

Published online: 21 April 2012

(C) American College of Medical Toxicology 2012

\begin{abstract}
Introduction The use of designer drugs commonly marketed as bath salts or plant food has risen dramatically in recent years. Several different synthetic cathinones have been indentified in these products, including mephedrone, 3,4-methylenedioxypyrovalerone (MDPV), and 4-fluoromethcathinone (flephedrone). We report a case of bath salt intoxication with quantitative MDPV and flephedrone levels in a patient's serum and urine, and from the bath salt product.

Case Report A 23-year-old male with a prior psychiatric history arrived via EMS for bizarre behavior, suicidality, and hallucinations after reportedly insufflating a bath salt. He was found to have MDPV levels of 186 and $136 \mathrm{ng} / \mathrm{mL}$ in his serum and urine, respectively, and flephedrone levels of 346 and $257 \mathrm{ng} / \mathrm{mL}$ in the serum and urine, respectively. The white powder in question was found to contain $143 \mu \mathrm{g}$ MDPV and $142 \mu \mathrm{g}$ flephedrone per milligram powder. His psychosis and agitation resolved with lorazepam, droperidol, and observation in the emergency department.
\end{abstract}

This paper has not previously been presented and was not funded.

S. L. Thornton $(\bowtie) \cdot$ C. A. Tomaszewski

Division of Medical Toxicology,

Department of Emergency Medicine,

University of California-San Diego,

200 W Arbor Dr \#8925,

San Diego, CA 92103-8925, USA

e-mail: stephenthorntonmd@yahoo.com

S. L. Thornton

Veteran's Affairs Medical Center,

San Diego, CA, USA

\section{R. R. Gerona}

Department of Laboratory Medicine,

University of California-San Francisco,

San Francisco General Hospital,

San Francisco, CA, USA
Discussion Agitation, psychosis, movement disorders, tachycardia, and hypertension have all been attributed to the use of MDPV; there are no prior reports detailing clinical experience with flephedrone. Considering that our patient's serum flephedrone levels were twofold higher than his MDPV level, it is likely flephedrone contributed to his clinical toxicity. This case suggests the possibility that fluorinated cathinones, such as flephedrone, may have altered metabolism and/or elimination which may affect their course of clinical toxicity. This case highlights the evolving composition of synthetic cathinones found in bath salt products.

Keywords Synthetic cathinones · Flephedrone · MDPV · Psychosis

\section{Introduction}

The use of designer drugs commonly marketed as bath salts or plant food has risen dramatically in recent years [1]. Several synthetic cathinones have been indentified in these products, including mephedrone, 3,4-methylenedioxypyrovalerone (MDPV), and 4-fluoromethcathinone (flephedrone) [2, 3]. While agitation, psychosis, movement disorders, tachycardia, and hypertension have all been attributed to the use of MDPV, there are no reports detailing clinical experience with flephedrone $[2,4,5]$. We report a case of the use of a bath salt product found to contain both MDPV and flephedrone which resulted in severe psychosis confirmed with quantification of these drugs in serum, urine, and in the product itself.

\section{Case Report}

A 23-year-old man with a prior psychiatric history arrived via ambulance to the emergency department (ED) for 
bizarre behavior, suicidality, and hallucinations after reportedly insufflating a bath salt. This bath salt was a white powder in an unlabeled vial. The patient was agitated and complained of visual, tactile, and auditory hallucinations. He stated snakes were crawling on him and in his bed. His initial vital signs revealed: blood pressure, $133 / 68 \mathrm{mmHg}$; heart rate, $109 \mathrm{bpm}$; temperature, $98.4^{\circ} \mathrm{F}\left(36.9^{\circ} \mathrm{C}\right)$; and respirations, 21 breaths/minute with an oxygen saturation of $100 \%$ on room air. He was diaphoretic and tachycardic with mydriasis. There was no evidence of trauma. The remainder of his physical exam was unremarkable. Due to agitation, he was physically and chemically restrained. A total of $6 \mathrm{mg}$ of lorazepam and $2.4 \mathrm{mg}$ of droperidol were given intravenously over $90 \mathrm{~min}$ to sedate him. His basic metabolic panel was essentially normal with sodium of $143 \mathrm{mmol} / \mathrm{L}$ (normal, 136-145) and creatinine of $1.10 \mathrm{mg} / \mathrm{dL}$ (normal, 0.67-1.17). Per the medical record, he had a history of being prescribed clonazepam, quetiapine, aripiprazole, valproic acid, and lithium. Results of his serum toxicology tests were negative for ethanol, acetaminophen, lithium, and valproic acid. A urine drug immunoassay (ONLINE DAT II, Roche Diagnostics) was positive for only tetrahydrocannabinoids (cutoff, $100 \mathrm{ng} / \mathrm{mL}$ ). The patient remained sedated in the next $5 \mathrm{~h}$. Upon awakening, he was no longer hallucinating or suicidal. He admitted to insufflating $1 \mathrm{~g}$ of the bath salt product approximately $30-60 \mathrm{~min}$ prior to presentation. $\mathrm{He}$ could not remember the brand name of this product or where he obtained it. He stated he had used this bath salt product before and denied any similar events. The patient was evaluated by psychiatry, and a differential diagnosis of schizoaffective disorder, bipolar disorder, or psychosis secondary to bath salt use was offered. Within $8 \mathrm{~h}$ of his arrival to the ED, he was discharged with planned follow-up. Serum, urine, and the bath salt product were sent for testing using liquid chromatographytime-of-flight mass spectrometry (LC-TOF/MS) (TOF 6230, LC 1260, Agilent) [6]. The left-over powder in the bath salt product jar weighed $195 \mathrm{mg}$. Thirty-nine different cathinones were screened for. As shown in Fig. 1, LC-TOF/MS testing of the bath salt product revealed both MDPV and flephedrone at concentrations of 143 and $142 \mu \mathrm{g} / \mathrm{mg}$ product, respectively. Our experience through observation and purchasing of these bath salt products is that similarly sized jars are frequently labeled as containing $500 \mathrm{mg}$ of powder. Potentially then, this bath salt product may have contained about $71.5 \mathrm{mg}$ MDPV and $72 \mathrm{mg}$ flephedrone per $500 \mathrm{mg}$ product. Caffeine was also detected in the product at a concentration of $102 \mu \mathrm{g} / \mathrm{mg}$ which is similar to that found in brewed coffee [7]. The patient's serum and urine were found to contain MDPV at concentrations of 186 and $136 \mathrm{ng} / \mathrm{mL}$, respectively, and flephedrone at concentrations of 346 and $257 \mathrm{ng} / \mathrm{mL}$, respectively. Formula matches to two common metabolites of MDPV - catechol pyrovalerone and methylcatechol pyrovalerone-were also detected in the patient's urine. Caffeine was detected in the serum and urine at concentrations of 387 and $367 \mathrm{ng} / \mathrm{mL}$, respectively. A comprehensive LC-TOF/MS screen evaluating for the presence of 309 other drugs in the blood and urine was negative.

\section{Discussion}

MDPV and flephedrone are synthetic cathinones, which are analogs of the naturally occurring cathinone found in khat (Catha edulis). Specifically, MDPV is a derivative of pyrovalerone which itself is a DEA schedule IV cathinone ana$\log$. MDPV differs from pyrovalerone by the addition of a methylenedioxy ring similar to that found in methylenedioxymethamphetamine (MDMA), the primary component of most "Ecstasy" products [8]. Figure 2 shows the structures of MDMA, MDPV, and flephedrone. MDPV has been identified in many bath salt products sold over the internet, in convenience stores, and by smoke shops. MDPV was made a DEA schedule I drug as of October 21, 2011 [2, 7]. Flephedrone is a fluorinated analog of methcathinone and has recently been identified as an emerging designer drug [3, 9]. We believe this to be the first report documenting both MDPV and flephedrone in a bath salt product in the USA.

MDPV is reported to be a potent monoamine reuptake inhibitor and manifest clinical effects similar to methamphetamine and MDMA [5, 10]. MDPV shares structural similarity with MDMA, a known serotonergic agent, and has been reported to cause serotonin toxicity [11, 12]. Other synthetic cathinones have been demonstrated to cause direct dopamine release and have significant effects on serotonergic receptors [13]. This serotonergic effect may explain the vivid visual hallucinations seen in our patient. It remains to be determined if MDPV has particularly potent CNS effects compared to other synthetic cathinones. Along with hallucinations, other symptoms that have been reported with confirmed or suspected MDPV exposures include tachycardia, hypertension, chest pain, dyspnea, myoclonus, and agitation $[2,4,5]$. Antonowicz et al. describes two cases of paranoid psychosis without hallucinations attributed to the use of an alleged MDPV product; however, they were unable to confirm the presence of MDPV in serum, urine, or the product [4]. Spencer et al. described four cases of MDPV exposures - including one death - confirmed with urine and serum levels though no product was tested [5]. Another death was attributed to MDPV use in Michigan, though body fluid levels were not reported and the product was not tested [1]. Spiller et al. reported on a poison center series of 236 alleged synthetic cathinone exposures, including one death, of which there were 13 serum and 4 urine confirmed MDPV exposures. As this was a retrospective study, they did not specifically comment on the clinical presentations of 


\section{a}

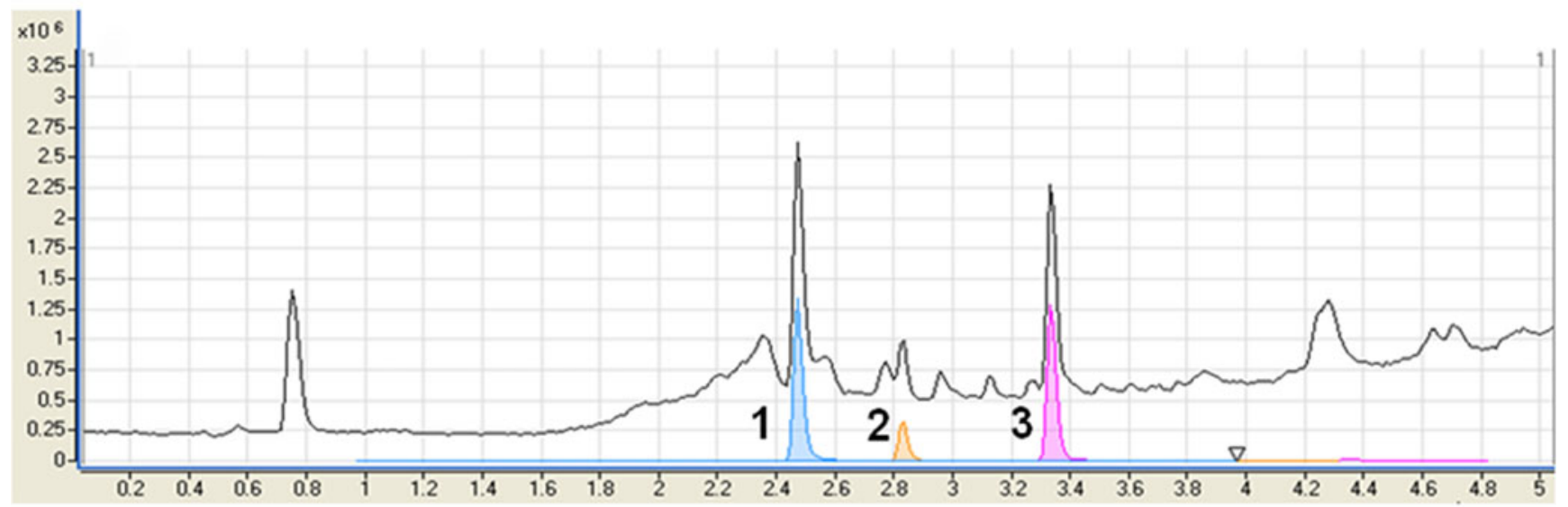

b

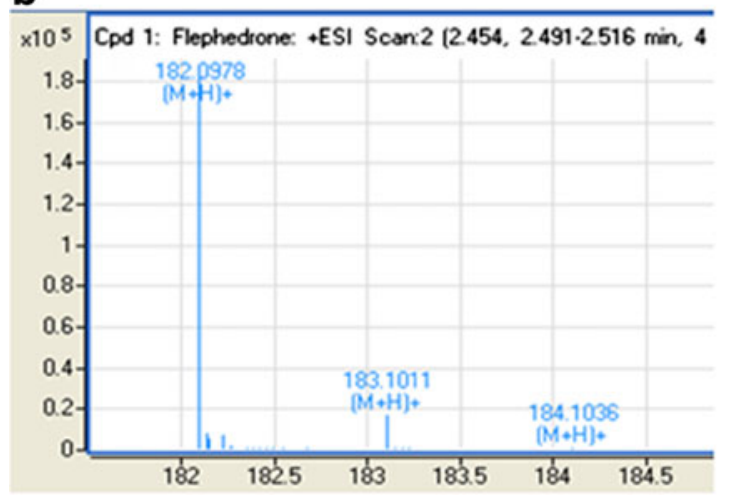

Fig. 1 Chromatograms and spectra obtained from the LC-TOF/MS analysis of the white powder. a Total ion chromatogram (black trace) obtained for the methanol extract of the white powder superimposed with the extracted ion chromatograms of compounds with confirmed

the MDPV-positive patients nor were they able to determine the concentration of MDPV in any associated products [2]. Our patient's MDPV levels were consistent with Spiller et al.'s report. Murray et al. describes a death attributed to MDPV with reported serum levels similar to ours but significantly higher urine levels [14]. No product was tested.

Compared to MDPV, there is much less clinical experience with flephedrone. In addition to their typical amphetamine-like effects, it is believed that para-halogenated phenylethylamines such as flephedrone may exhibit enhanced serotonergic effects [15]. This is thought to occur because halogenation of phenylethylamines at the para-position prevents metabolism via para-hydroxylation thereby resulting in a prolonged half-
C

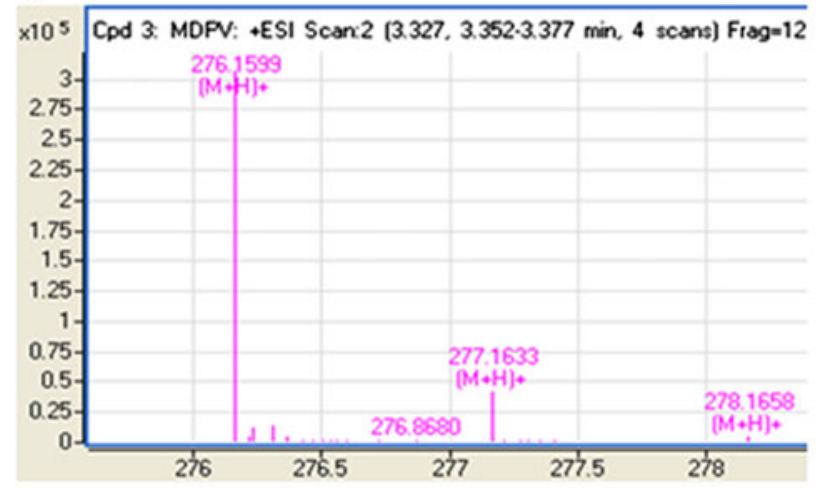

retention time and accurate mass matches-(1) flephedrone, (2) caffeine, and (3) MDPV obtained. b and $\mathbf{c}$ The corresponding mass spectra obtained for flephedrone (b) and MDPV (c) from a

life and clinical effect. This could explain why our patient's flephedrone levels were greater than the corresponding MDPV levels. To our knowledge, there are no prior human case reports detailing either clinical toxicity from flephedrone or quantification in biologic specimens. Considering that our patient's serum flephedrone levels were twofold higher than his MDPV level, it is likely flephedrone contributed to his clinical toxicity.

It is also notable that both the MDPV and flephedrone serum levels were much higher than the corresponding urine levels even though urine was collected $1 \mathrm{~h}$ after the serum. This likely represents recent exposure to these drugs, as per the patient's history, or could suggest decreased metabolism a<smiles>CC(N)Cc1ccc2c(c1)OCO2</smiles>

b<smiles>CCCC(C(=O)c1ccc2c(c1)OCO2)N1CCCC1</smiles>

C<smiles>CNC(C)C(=O)c1ccc(F)cc1</smiles>

Fig. 2 Structures of a methylenedioxyamphetamine (MDMA), b methylenedioxypyrovalerone (MDPV), and $\mathbf{c}$ 4-fluoromethcathinone (flephedrone) 
and excretion of the parent drugs. Studies show that both MDPV and halogenated cathinones undergo extensive hepatic metabolism $[16,17]$. Genetic heterogeneity in the metabolism of these drugs may play a role in cases of severe intoxications and warrants further investigation.

The bath salt product our patient claimed to have insufflated contained $143 \mu \mathrm{g}$ MDPV and $142 \mu \mathrm{g}$ flephedrone per milligram of product. To our knowledge, this is the first report of actual concentrations of MDPV or flephedrone in a bath salt product. This novel information may allow some insight into the potency of these products. The patient's claim that he insufflated $1 \mathrm{~g}$ of the bath salt product is likely unreliable and considerably higher than anecdotal reports of bath salt users abusing $25 \mathrm{mg}$ or less of the product per session [10].

Recommended care for patients exhibiting toxicity from synthetic cathinones is aimed at controlling the sympathomimetic excess [2]. Our patient seemed to benefit from the use of both lorazepam and droperidol. The latter may have been useful due to its dopamine antagonism. Prolonged observation and/or hospital admission may be needed. In one poison center study, less than $50 \%$ of reported synthetic cathinone exposures were discharged from the ED [2].

\section{Conclusion}

MDPV and flephedrone are synthetic cathinones which can cause significant sympathomimetic effects, psychosis, and hallucinations. This patient presented with significant psychosis and a mild sympathomimetic syndrome. He recovered in the ED with chemical sedation and observation. To our knowledge, this is the first case in which both MDPV and flephedrone levels were quantitatively determined in the product, serum, and urine and highlights the evolving composition of the synthetic cathinones found in bath salt products.

Conflict of Interest There are no conflicts to declare.

\section{References}

1. Centers for Disease Control and Prevention (CDC) (2011) Emergency department visits after use of a drug sold as "bath salts"Michigan, November 13, 2010-March 31, 2011. MMWR Morb Mortal Wkly Rep 60(19):624-627
2. Spiller HA, Ryan ML, Weston RG et al (2011) Clinical experience with and analytical confirmation of "bath salts" and "legal highs" (synthetic cathinones) in the United States. Clin Toxicol (Phila) 49 (6):499-505

3. Reitzel LA, Dalsgaard PW, Müller IB, et al. (2012) Identification of ten new designer drugs by GC-MS, UPLC-QTOF-MS, and NMR as part of a police investigation of a Danish Internet company. Drug Test Anal (in press)

4. Antonowicz JL, Metzger AK, Ramanujam SL (2011) Paranoid psychosis induced by consumption of methylenedioxypyrovalerone: two cases. Gen Hosp Psychiatry 33(6):640

5. Spencer JW, Long C, Scalzo AJ et al (2011) Acute psychiatric, cardiopulmonary, and neurologic effects of laboratory-confirmed use of methylenedioxypyrovalerone (MDPV) "bath salts". (Abstract). Clin Toxicol (Phila) 49:515-627

6. Lung DD, Gerona RR, Wu AH, et al (2012) Confirmed glyburide poisoning from ingestion of "Street Valium". J Emerg Med (in press)

7. Bunker ML, McWilliams M (1979) Caffeine content of common beverages. J Am Diet Assoc 74(1):28-32

8. Morefield KM, Keane M, Felgate P et al (2011) Pill content, dose and resulting plasma concentrations of 3,4-methylendioxymethamphetamine (MDMA) in recreational 'ecstasy' users. Addiction 106 (7):1293-1300

9. Brandt SD, Sumnall HR, Measham F et al (2010) Analyses of second-generation 'legal highs' in the UK: initial findings. Drug Test Anal 2(8):377-382

10. Drug Enforcement Administration (DEA) (2011) Department of Justice. Schedules of controlled substances: temporary placement of three synthetic cathinones in Schedule I. Final order. Fed Regist 76(204):65371-65375

11. Yubero-Lahoz S, Ayestas MA Jr, Blough BE et al (2012) Effects of MDMA and related analogs on plasma 5-HT: relevance to 5-HT transporters in blood and brain. Eur J Pharmacol 674 (2-3):337-344

12. Mugele J, Nañagas KA, Tormoehlen LM (2012) Serotonin syndrome associated with MDPV use: a case report. Ann Emerg Med (in press)

13. Hadlock GC, Webb KM, McFadden LM et al (2011) 4Methylmethcathinone (mephedrone): neuropharmacological effects of a designer stimulant of abuse. J Pharmacol Exp Ther 339(2):530-536

14. Murray BL, Murphy CM, Beuhler MC (2012) Death following recreational use of designer drug "bath salts" containing 3,4-methylenedioxypyrovalerone (MDPV). J Med Toxicol 8 (1):69-75

15. Fuller RW (1978) Structure-activity relationships among the halogenated amphetamines. Ann N Y Acad Sci 305:147-159

16. Meyer MR, Du P, Schuster F et al (2010) Studies on the metabolism of the $\alpha$ pyrrolidinophenone designer drug methylenedioxypyrovalerone (MDPV) in rat and human urine and human liver microsomes using GC-MS and LC-high-resolution MS and its detectability in urine by GC-MS. J Mass Spectrom 45(12):1426-1442

17. Pawlik E, Plässer G, Mahler H et al (2012) Studies on the phase I metabolism of the new designer drug 3-fluoromethcathinone using rabbit liver slices. Int J Legal Med 26:231-240 